\title{
CONTRIBUIÇÃO DA GEOMORFOLOGIA ANTRÓPICA NA CARACTERIZAÇÃO dO MACIÇO DO Bonilha, Região Metropolitana de São Paulo
}

\author{
Breylla Campos Carvalho ${ }^{1}$ \\ Déborah de Oliveira ${ }^{2}$
}

\begin{abstract}
Resumo: As atividades humanas, nas últimas décadas, têm tido enorme impacto sobre as paisagens naturais, tendo como conseqüencias eventos de desastres naturais, que culminam com prejuizos naturais, sociais e econômicos. Diante deste cenário, a presente pesquisa tem como objetivo analisar a atuação da sociedade como agente geomorfológico, ou seja, como a urbanização irá interferir/acelerar os processos geomorfológicos de uma determinada área. Para tanto, o Maciço do Bonilha e seu entorno, na Região Metropolitana de São Paulo, foi adotado como área de estudo. A fim de atingir o objetivo foram feitos levantamentos bibliográficos e cartográficos, elaboração de material cartográfico e realização de trabalhos de campo para conferência dos produtos confeccionados. Foram elaborados os mapas de evolução da mancha urbana e de susceptibilidade a deslizamentos da área de estudo, mostrando que áreas com altas declividades e ocupadas apresentam susceptibilidade instalada. Os resultados obtidos reiteram a problemática ambiental do agravamento dos desastres naturais em áreas predispostas a riscos naturais ocupadas por moradias irregulares e autoconstrução.
\end{abstract}

Palavras-chave: Geomorfologia Antrópica; Urbanização; Maciço do Bonilha; Região Metropolitana de São Paulo.

\section{Anthropic geomorphology contribution in Massive Bonilha characterization, São Paulo Metropolitan Region}

\begin{abstract}
Human activities, in recent decades, have had enormous impact on natural landscapes, and having as consequences natural disasters events, that culminate with natural, social and economic losses. Against this background, this research aims to analyze the society performance as a geomorphological agent, i.e. how urbanization will affect / accelerate geomorphological processes in a particular area. Therefore, the Massif Bonilha and its surroundings, in the Metropolitan Region of São Paulo, was adopted as the study area. In order to achieve the goal were made literature and mapping surveys, preparation of cartographic material and conducting field work conference for the products manufactured. Maps of the urban development and susceptibility to landslides in the study area were prepared, showing that areas with steep slopes and occupied have susceptibility installed. The results reaffirm the environmental problem of worsening natural disasters in areas prone to natural hazards occupied by irregular housing and auto self construction.
\end{abstract}

Key-Words: Anthropic Geomorphology; Urbanization; Bonilha Massif; São Paulo Metropolitan Region.

\footnotetext{
${ }^{1}$ Bacharelado e Licenciatura em Geografia pela Universidade de São Paulo, mestranda em Oceanografia da Universidade do Estado do Rio de Janeiro. E-mail: b.carvalho@usp.br

${ }^{2}$ Bacharelado em Geografia pela Universidade de São Paulo, licenciatura em Geografia pela Universidade de São Paulo, Mestrado em Geografia Física pela Universidade de São Paulo e Doutorado em Geografia Física pela Universidade de São Paulo. Professora do Departamento de Geografia da Universidade de São Paulo. E-mail: debolive@usp.br DOI: 10.7154/RDG.2012.0024.0003
} 


\section{INTRODUÇÃO}

Nos últimos séculos, as atividades humanas têm impactado fortemente o meio ambiente, seja por meio da industrialização, da agricultura, etc. Em muitos casos, esses impactos se associam à ocorrência de riscos geomorfológicos, comumente chamados de desastres naturais, por exemplo, inundações, deslizamentos de terra, avalanche de neve, erosão do solo, entre outros, que acabam por afetar essas mesmas atividades, as vezes com resultados catastróficos.

Segundo Alcántara-Ayala (2002), os desastres naturais ocorrem em todo o mundo, no entanto, o seu impacto é maior nos países em desenvolvimento, onde ocorrem com muita freqüência. Estes locais sofrem, em geral, os efeitos da urbanização acelerada, sobretudo nas grandes metrópoles desses países, resultando no aparecimento de diversas pressões antropogênicas. Tais interferências podem modificar e/ou acelerar alguns processos geomorfológicos, configurando um quadro de áreas de risco.

Diante disto, este trabalho tem por objetivo entender como a ação da sociedade escultura o relevo, ou seja, como a urbanização acelera e/ou interfere nos processos de natureza geomorfológica, especialmente os deslizamentos.

Tais situações de risco associam-se a fenômenos de natureza geológica, climática e biogeográfica, com destaque para os escorregamentos, e têm como consequência constantes acidentes geomorfológicos, acarretando em perdas de vidas humanas e enormes prejuízos econômicos. Esses acidentes aumentam no período de chuvas intensas, como as verificadas no início de 2010, associadas à ocupação de encostas de forma desordenada.

Os problemas referentes a moradias precárias são graves, comumente favelas e escorregamentos, uma combinação arriscada, principalmente nos períodos de chuvas intensas, com perdas materiais, danos à saúde pública e em alguns casos, perdas humanas (INPE, 2010), reiterando a importância de discussão sobre o tema.

O presente estudo se justifica pela sua atualidade e por abordar as relações entre os aspectos naturais e sociais na compreensão da produção do espaço, levando em conta que o modelo de desenvolvimento baseado em uma sociedade de hiperconsumo que associada a um modelo de exploração que superexplora os recursos naturais, afetando o equilíbrio dos ecossistemas, e assim intensificando os impactos ambientais, sociais e econômicos, apresenta desdobramentos globais, mais sensíveis ainda em escala local. 
A ocupação do homem numa determinada área rompe a dinâmica geomorfológica natural dela, ocasionando a intensificação dos processos erosivos e deposicionais (PELOGGIA, 1998; FUJIMOTO, 2002), temas analisados pela Geomorfologia Antrópica, que é parte da ciência que estudará as transformações causadas pelo homem ao meio ambiente através da relação de combinação de fatores físicos e os impactos provocados pela ação humana, que induzem ou aceleram os processos geomorfológicos, muitas vezes dando a eles um caráter catastrófico (SANTOS FILHO, 2007).

Como coloca NIR (1983), "a atividade de um homem sozinho não pode alterar muito o relevo, entretanto, o homem não atua sozinho, mas como parte da sociedade". Logo, temos que a Geomorfologia Antrópica depende do social e assim dos aspectos demográficos, econômicos e iconográficos da humanidade.

Partindo do pressuposto de que a geomorfologia é o estudo das formas e em particular sua natureza, origem, processo de desenvolvimento e material de composição, podemos atrelar a geomorfologia ao uso humano do meio ambiente, pois muitas pesquisas geomorfológicas são potencialmente aplicáveis para alguns problemas de planejamento ambiental.

Goudie (1986) também observa o papel do homem como criador de formas de relevo e modificador das operações dos processos geomorfológicos. Desta forma, examinar os processos e em particular o seu ritmo de operação tem servido para realçar a parte atuada por humanos na modificação das paisagens naturais.

Segundo Nir (1983), temos a impressão de que é recente o fato do homem ser considerado um agente geomorfológico e de fato esta percepção é suscitada com afinco a partir de 1960, como ele mesmo coloca "o conceito já existia, em um estado embrionário". Porém são poucos os trabalhos que associam a geomorfologia e as catástrofes naturais diretamente, de acordo com Alcántara-Ayala (2002), havendo poucas publicações nesta interface (por exemplo, Okuda, 1970; Verstappen, 1989; Rosenfeld, 1994).

Fatores importantes no que tange os estudos da Geomorfologia Antrópica são os relacionados a demografia, sociedade e economia. Só a existência humana constitui uma parte completa no processo de produção do ambiente e com certas ferramentas ele intensifica sua intervenção.

Temos que as principais mudanças ambientais consequentes da urbanização refletem nos elementos da natureza (relevo, vegetação, corpos hídricos, clima, etc.) presentes nas áreas 
urbanizadas. Logo, o conhecimento da área urbanizada é imprescindível na gestão do território e definidor de políticas públicas para o planejamento e ordenamento territorial. Atentando-se a urbanização e ao povoamento nas grandes cidades, podemos observar a urbanização como um fenômeno que adquire características particulares com a mudança de escala, não apenas como uma forma de organização do espaço, mas também como um fenômeno social e espacial complexo. Assim, o processo de urbanização se revela na produção de um novo espaço, em que há o momento da redefinição da metrópole, com sua explosão, extensão das periferias, reprodução do espaço num outro patamar e com graus de dependência das áreas entre si (CARLOS, 2009).

Para o presente trabalho, dar-se-á mais atenção a questão da moradia e a ocupação de áreas de risco nas grandes cidades. Sabe-se que o ato de morar faz parte da própria história do desenvolvimento da vida humana, logo não se pode viver sem ocupar lugar no espaço, porém as características deste ato mudam de acordo com cada contexto sociopolítico e econômico. Assim, o ato de morar apresenta um conteúdo político, social, econômico e principalmente espacial, que refletem em características diversas da habitação, logo concretizam uma produção diferenciada da cidade (GOMES et al., 2003).

Parte da população que foi excluída do processo de moradia e de outros processos, produz a cidade de maneira clandestina, sendo a autoconstrução a alternativa encontrada para suprir a demanda pela moradia (GOMES et al., 2003).

Tem-se aí o surgimento das chamadas áreas clandestinas, com a predominância de favelas, cortiços e vilas, que não oferecem condições dignas de moradia a uma boa parcela da população e geralmente se encontram em áreas distantes do centro da cidade, criando as externalidades urbanas.

A partir dos anos 1970, o traçado urbano da RMSP tem sofrido mais alterações em virtude dos novos parâmetros de ocupação, a implantação do Metrô, as políticas de desapropriação, as grandes obras viárias, entre outros. É durante a década de 1970, que se intensifica a expansão da mancha urbana em direção às áreas periféricas (KOWARICK, 1979). Na atualidade, nossa sociedade apresenta o preço do solo urbano cada vez mais raro e caro, condições estas que levam as pessoas de menor poder aquisitivo a ocuparem áreas de risco e insalubres (GOMES et al., 2003).

Para abordar tal temática, foi escolhida uma área da Região Metropolitana de São Paulo (RMSP) que abarcasse toda essa problemática e o qual pudesse ser analisada, pautada nos 
aspectos sociais (uso do solo, evolução da mancha urbana, industrialização) e físicos (dados morfométricos, geologia, relevo, solos, clima e vegetação). A área escolhida para ser estudada, o Maciço do Bonilha, encontra-se nos municípios de São Bernardo do Campo e de Santo André, em que grande parte está situada em uma Unidade de Conservação, o Parque Regional do Pedroso, e a outra parte caracteriza uma parcela da periferia desses municípios do ABC Paulista.

Temos que os estudos geomorfológicos para a área de estudo são importantes, mostrando a "pertinência da consideração do relevo e suas propriedades na organização do território" (ABREU, 1985), pois "se queremos compreender a ação do homem, não devemos separar a sociedade do meio ambiente que a rodeia" (SCHMITHÜSEN ${ }^{3}, 1970$ apud ABREU, 1985).

Assim, este trabalho busca corroborar nesta discussão, propondo uma análise integrada sobre a estrutura e a dinâmica dos agentes naturais e sociais na geomorfologia das áreas urbanas. Para tanto, o trabalho se apoiou no levantamento bibliográfico e cartográfico, nos trabalhos de campo e na elaboração de mapas que sintetizassem os fenômenos observados.

\section{O Maciço do Bonilha e seu Entorno}

O recorte espacial realizado para a análise do presente trabalho compreende o Maciço do Bonilha e a região do seu entorno abarcando bairros dos municípios de Santo André e São Bernardo do Campo, na Região Metropolitana de São Paulo, também conhecido como ABC Paulista (Figura 1).

O Maciço do Bonilha se localiza no extremo sudeste do município de São Bernardo do Campo, no bairro do Montanhão, na divisa com o município de Santo André, tendo seu pico a uma altitude de 986,50 metros, ponto mais alto do ABC Paulista.

A área de estudo está inserida numa região periférica, de ambos os municípios citados, com bairros muito populosos, carência de infraestrutura, altos índices de violência, inúmeras áreas de risco, muitas delas interditadas pela Defesa Civil. Soma-se a isso que parte da área do maciço se encontra na Área de Proteção aos Mananciais, neste caso referente à Represa Billings e quase sua totalidade está inserida dentro da Unidade de Conservação do Parque do Pedroso, sob jurisdição da SEMASA (Saneamento Ambiental de Santo André).

\footnotetext{
${ }_{3}^{3}$ SCHMITHÜSEN, J. Die Aufgabenkreise der geographischen Wissenschaft. Geographische Rundschau, Vol. 22, n. 11, 1970, p. 431-443.
} 


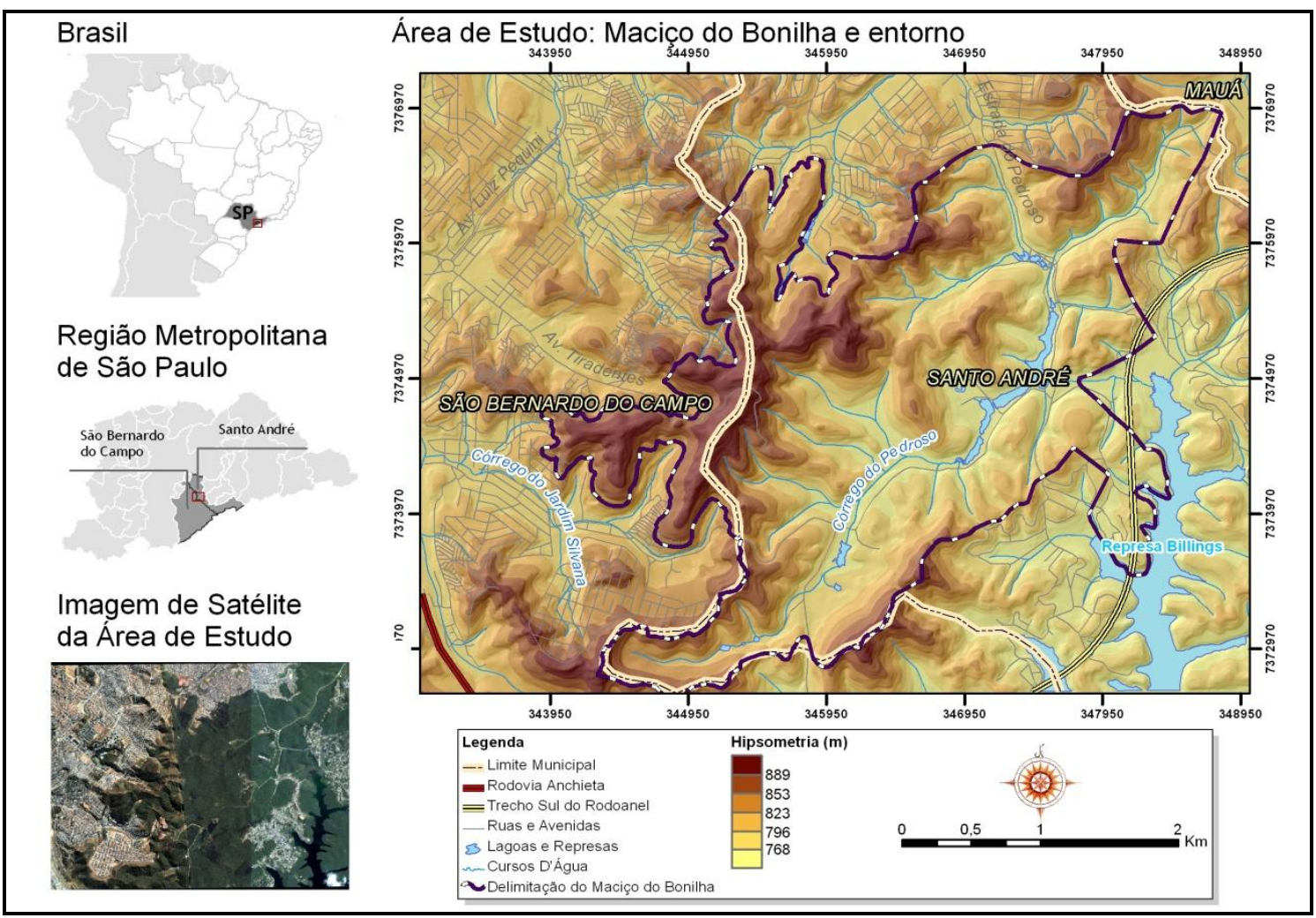

Figura 1 - Mapa de localização do Maciço do Bonilha e seu entorno.

\section{Fatores Demográficos e Assentamento Urbano}

A intensa atividade industrial vivida pela região do ABC Paulista entre as décadas de 1950 e 1970, serviu de chamariz para pessoas em busca de emprego, configurando num crescimento migratório, entre as décadas de 60 e 80.

Como desdobramento, a área urbana foi sendo parcelada para o assentamento habitacional acompanhada de pequeno comércio e prestação de serviços para essa população. $A$ isto, soma-se o surgimento de favelas, iniciando-se em 1950, mas tendo elevado crescimento na década de 80 , pois nesta década continuam os fluxos migratórios para a região, porém o setor industrial não apresenta crescimento, haja vista que nesse período o governo federal incentiva a interiorização dos parques industriais em detrimento das regiões metropolitanas. É nesta década também que haverá forte presença de ocupações precárias e clandestinas nas áreas de proteção aos mananciais, devido à demanda por habitações e ao alto custo do solo urbano nas áreas já urbanizadas. 
A maioria dos principais centros metropolitanos - cidades como São Paulo, Rio de Janeiro, Recife, Belo Horizonte, Salvador - apresenta de $20 \%$ a $40 \%$ de população residente em favelas (MARICATO, 2001). No ABC Paulista, no período de 1980 a 1996, a população de favela cresceu aproximadamente quatro vezes mais que a total. A taxa geométrica de crescimento anual (TGCA) da população total residente no ABC, para o período de 1980 a 1991, é de 2,13\%; para o período de 1991 a 1996, de 1,68\%. A TGCA da população total de favelas, nos mesmos períodos, é de $9,21 \%$ e $6,88 \%$, respectivamente (DENALDI, 2004). Na tabela 1 é apresentado o total da população que mora em favelas nos municípios estudados, mostrando que a tendência de aumento desse tipo de população ainda é crescente entre os anos 1991 e 2000.

Tabela 1 - Número de habitantes moradores de favelas.

\begin{tabular}{ccc}
\hline & 1991 & $\mathbf{2 0 0 0}$ \\
\hline Santo André & 53.985 & 70.022 \\
São Bernardo do Campo & 80.139 & 147.483 \\
\hline
\end{tabular}

Fonte: Meyer et al. (2004).

Essas são tendências gerais no processo de formação da metrópole, em que nesse período se tornará mais espraiada e difusa, logo se torna mais desigual e polarizada, promovendo desta forma a segregação e a auto-segregação (no caso deste trabalho atentar-se-á para o fator de segregação).

No desenrolar desse processo, hoje se tem que devido às condições topográficas e a forma como a parte urbanizada encontra-se adensada, tanto em Santo André como em São Bernardo, os espaços disponíveis ficaram escassos dentro da malha urbana, devido, em grande parte, pela elevação do valor do solo urbano nas áreas centrais e urbanizadas, fato que acaba por inviabilizar o acesso a terra nestas áreas por parte das camadas mais carentes da população, que vão morar em regiões afastadas do centro.

Nas regiões periféricas, essa população constrói casas, em geral sem infraestrutura, denominadas autoconstruções, muitas vezes sem saneamento básico, rede de água e esgoto e energia elétrica "oficial", com casas em geral construídas em alvenaria, de maneira precária, e barracos de madeira. Em geral, essas moradias se concentram em áreas de risco, com altas declividades, sujeitas a desabamentos e deslizamentos, ou em planícies aluviais, sujeitas a enchentes e erosão dos solos (Figura 2). 

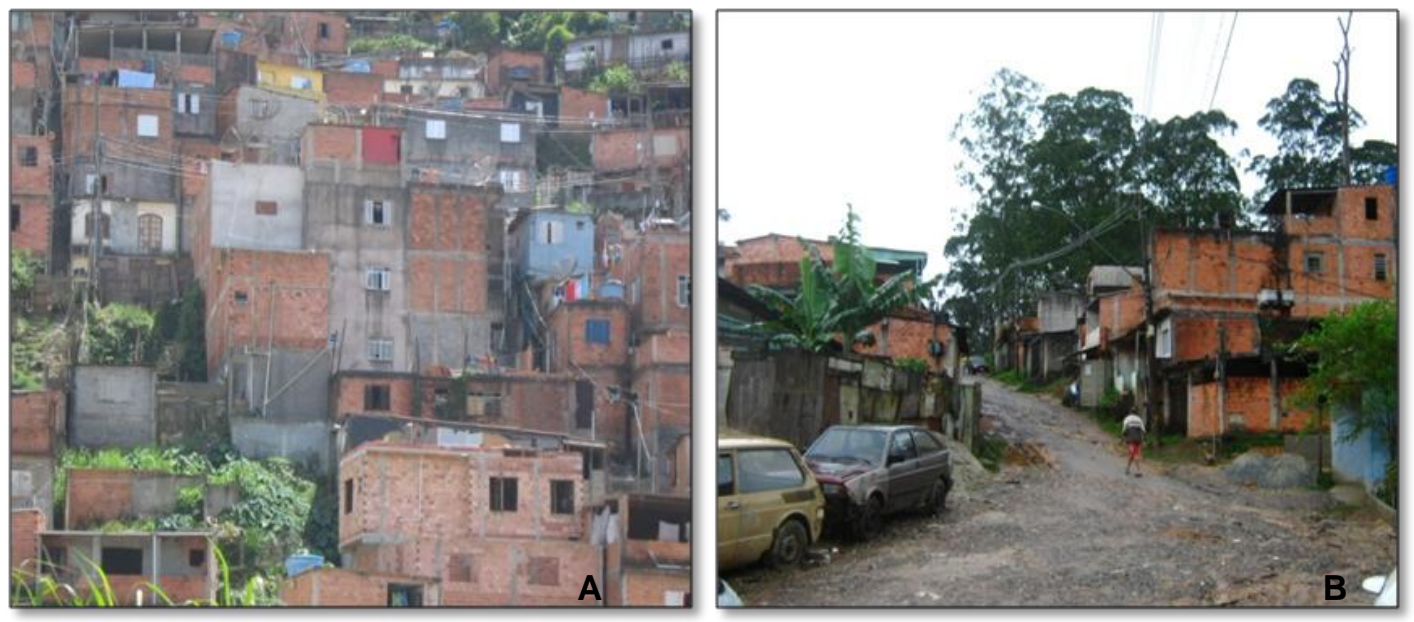

Figura 2 - Regiões periféricas do ABC Paulista. A- Favela do Montanhão, em São Bernardo do Campo; B - Favela Pintassilva, em Santo André (04/03/2010)

\section{Aspectos Físicos da Área de Estudo}

Dentro da divisão geomorfológica do Estado de São Paulo proposta por Almeida (1974), a área de estudo está inserida na província do Planalto Atlântico, na zona do Planalto Paulistano. Esta é uma província de terras altas predominantemente cristalinas, com variedades de aspectos topográficos estruturais e genéticos (Figura 3).

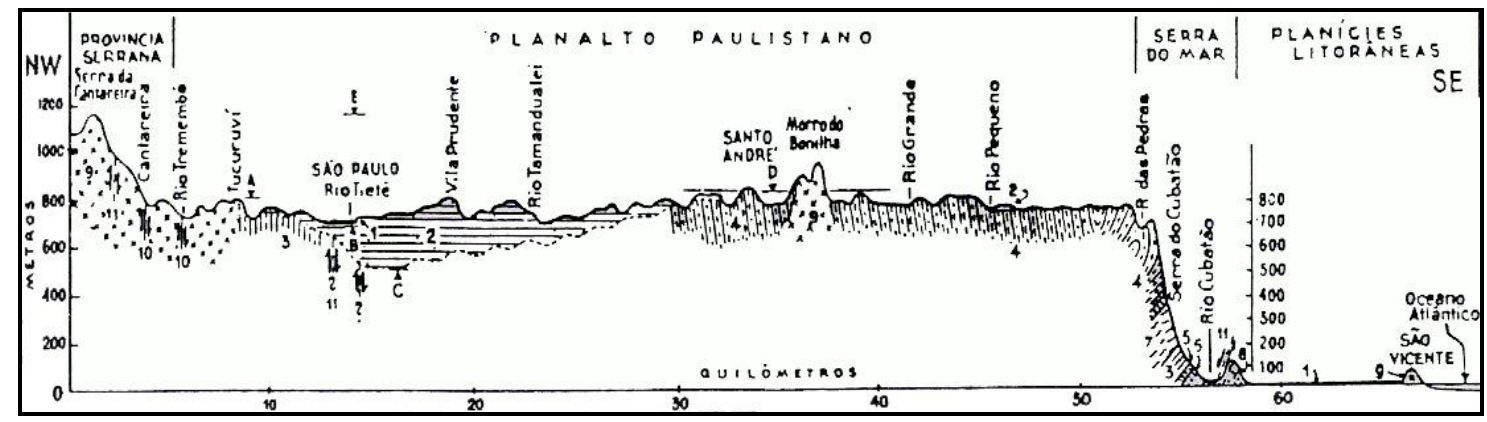

Figura 5 - Seção morfológico-estrutural da Serra da Cantareira ao oceano, através do Planalto Paulistano e Serra do Mar. 1 - Depósitos quaternários das várzeas; 2 - camadas de São Paulo; 3 - filitos; 4 - micaxistos (e gnaisses micáceos); 5 - quartzitos; 6 - calc calcáreos; 7 - biotita-ganisses (de origem migmática); 8 -

migmatitos facoidais; 9 - granitos; 10 - falhas provadas; 11 - falhas prováveis. A - Nível máximo atingido pelas camadas de São Paulo; B - nível da soleira de Barueri (710 m); C - máxima profundidade conhecida, da bacia de São Paulo (543 m); D - nível médio da superfície de erosão do Alto Tietê (825 e 850 m). E - nível da peneplanície do Japi. Fonte: Almeida (1958).

Ao norte do Bonilha dá-se início a mais homogênea subunidade geomórfica do Planalto Atlântico, separando a superfície cristalina do Alto da Serra em relação às colinas da bacia sedimentar de São Paulo, fazendo parte do chamado "reverso continental da Serra do Mar" (AB'SABER, 1957). A topografia que predomina no entorno se caracteriza por amplitudes 
médias de até 50 metros, já no Bonilha essa variação chega a 200 metros, tendo declividades superiores a $20 \%$, localmente atingindo $50 \%$ ou mais. Este fato acaba por inviabilizar o uso urbano como uma área crítica e de risco a ocupação (SCIFONI \& MARTINS, 1997).

A área apresenta litologia pertence ao Escudo Atlântico, micaxistos nas vertentes norte e oeste e gnaisses nas vertentes sul e leste. A origem estrutural pode estar relacionada com dobramentos localizados, associados a pequenas falhas orientadas no sentido SW-NE, direção predominante no Escudo Atlântico. Existem evidências de estruturas de dobramento em pacote de rocha. Segundo o estudo de Ab'Saber (1957), após a formação do Maciço do Bonilha há evidências de que o ciclo de erosão pós-pliocênica tenha alcançado um adiantado estágio de desenvolvimento.

Tem-se que as estruturas antigas do Planalto Atlântico, nesta área, estão orientadas na direção geral ENE, com faixas de rochas metassedimentares exibindo metamorfismo em geral decrescente da borda atlântica do planalto para seu interior e faixas de biotita-gnaisses e de gnaisses graníticos que suportam os festões da Serra do Mar diante do Planalto Paulistano.

Internamente, há a presença de ampla faixa de micaxistos, da área marginal às grandes represas, sendo que estas rochas intercalam-se com camadas de quartzitos, pouco volumosas, e intrusões de granito cinzento de granulação fina e pegmatitos associados, e a noroeste há a presença de camadas de filitos (ALMEIDA, 1974).

O clima da região é do tipo mesotérmico, segundo a classificação de Köppen. A temperatura média é de $19,1^{\circ} \mathrm{C}$, tendo como máxima $36^{\circ} \mathrm{C}$ e mínima $0,5^{\circ} \mathrm{C}$ (SÃO BERNARDO DO CAMPO, $\mathrm{s}$. d.). A umidade relativa do ar chega a $80 \%$ e a pluviosidade anual tem o valor médio de 1169 $\mathrm{mm}$. Os fenômenos de garoa, neblina e cerração são freqüentes. O período mais chuvoso vai de outubro a março, variando os meses mais chuvosos entre janeiro, fevereiro e março. Já o período restante é o de maior estiagem, onde julho é predominantemente o mais seco.

A rede de drenagem se caracteriza por pequenos córregos e ribeirões, encaixados em suas vertentes na maior parte das vezes, não contendo planícies aluviais expressivas. Por possuírem vazão o ano todo, acabam por alimentar o lençol freático nos períodos de estiagem. Os índices pluviométricos na região adquirem grande energia potencial ocasionando erosão e deslizamentos nas áreas desmatadas e com solo exposto (SCIFONI \& MARTINS, 1997). 
A formação vegetal original era a floresta subtropical do Planalto, com araucárias disseminadas, que se estendia do Planalto Atlântico até o interior do Estado (HUECK, 1956). Esse é um tipo de vegetação que se desenvolve sobre solos oriundos de rochas do Escudo Cristalino, encontrando-se condicionada aos fatores climáticos locais (alta nebulosidade, umidade nos topos do maciço e duas estações bem marcadas, uma seca e outra chuvosa), tendo sua cobertura vegetal inserida dentro do ecossistema Mata Atlântica.

Houve uma perda da vegetação nativa em quase sua totalidade, se constituindo de campos limpos e sujos com arbustos e restos de mata e ocupação de culturas (AZEVEDO, 1958), apresentando pequenas manchas distribuídas pontualmente pelo território paulista.

A Unidade de Conservação do Parque Regional do Pedroso (Figura 1) se localiza na região periférica de Santo André, fazendo limite ao município de São Bernardo do Campo, rodeado por pequenas chácaras, residências, a favela Pintassilva, brejos, matas, próximo à Represa Billings. A área nasce da preocupação, verificada desde os anos 1960, quanto à preservação das reservas florestais e proteção aos mananciais. No parque e no seu entorno, há diversos tipos de formações vegetais, tais como mata atlântica, mata secundária, campos e brejos, apresentando uma ampla variação estrutural associada aos graus de perturbação antrópica (MATARAZZO-NEUBERGER, 1986; SÃO PAULO, 2004).

\section{MATERIAIS E MÉTODOS}

Para realização do presente trabalho foram feitas pesquisas bibliográficas, fotográficas e cartográficas nas bibliotecas de universidades do Estado de São Paulo, na prefeitura e no Museu de Santo André e no Serviço de Patrimônio Histórico de São Bernardo do Campo, para obtenção de informações sobre o Maciço do Bonilha e de seu entorno, bem como a realização de trabalhos de campo na área de estudo, resultando em produtos cartográficos que subsidiaram a análise proposta.

Para o mapeamento utilizou-se cartas topográficas do Sistema Cartográfico Metropolitano: folhas De Marchi e Pedroso (EMPLASA, 1980), na escala 1:10.000; imagens IKONOS; base cartográfica do Centro de Estudo da Metrópole (CEM), do Instituto Brasileiro de Geografia e Estatística (IBGE) e das prefeituras de Santo André e São Bernardo do Campo, no formato shapefile; e fotografias aéreas dos anos de 1962, 1972, 1994 e 2008. 
O material cartográfico produzido pela autora consistiu no mapeamento das feições morfométricas e morfológicas da área de estudo, a saber: mapa hipsométrico, mapa de declividade, mapa de formas de encosta e mapa de orientação de vertentes.

Para o desenvolvimento do mapa de evolução da mancha urbana realizou-se a fotointerpretação de fotografias aéreas através do software ArcGIS 9.2, em que foram traçados os polígonos de mancha urbana da área de estudo referente aos seguintes anos: 1962, 1972, 1994 e 2008. Por meio deste software foi possível quantificar as áreas e fazer, assim, uma análise quantitativa da evolução da mancha urbana da área em questão.

De maneira a sintetizar os dados referentes à ocupação urbana e morfologia e morfometria da área, foi elaborado um mapa de susceptibilidade a deslizamentos com a definição de três classes, modificando a proposta de (VIEIRA \& FURTADO, 2004). A proposta original define as classes de acordo com os seguintes parâmetros:

$\checkmark$ Instalada: áreas ocupadas com declividade acima de 30\%; a partir do centro de edificação, traçou-se uma circunferência de 15 metros de raio;

$\checkmark$ Potencial: foi desenhada uma faixa de 15 metros no entorno das áreas de susceptibilidade instalada; somaram-se a elas as áreas com declividades acima de $30 \%$ que não se encontravam ocupadas;

$\checkmark$ Baixa: demais áreas com declividade inferior a $30 \%$.

O presente trabalho definiu as classes de susceptibilidade da seguinte forma:

$\checkmark$ Instalada: áreas ocupadas com declividade acima de 30\%;

$\checkmark$ Potencial: áreas adjacentes às áreas instaladas e áreas não ocupadas com declividade superior a $30 \%$;

$\checkmark$ Baixa: demais áreas.

\section{RESULTADOS E DISCUSSÃO}

\section{Evolução da Mancha Urbana}

Buscando analisar a composição e a estrutura da paisagem do Maciço do Bonilha e de seu entorno, foi construído o mapa de evolução da mancha urbana (Figura 4). A evolução dessa mancha acompanha o curso da história do $A B C$ Paulista, mostrando um adensamento 
urbano maior no período pós década de 80 , onde haverá o incremento da população que passa a morar nas áreas periféricas da RMSP.

No ano referente a 1962 a área urbanizada correspondia a 212,4 hectares, sendo no ano de 1972 pouco mais que o dobro, com 491,7 hectares. No ano de 1994 esse número salta para 1210,4 hectares, tendo um leve aumento em 2008, com 1319,6 hectares. Na Tabela 2 são apresentados os valores percentuais em relação à área e percebe-se que até o ano de 2008, essa mancha é quase metade da área estuda. Um fator que freia esse adensamento populacional é a Unidade de Conservação do Parque do Pedroso, por ser uma área de proteção ambiental.

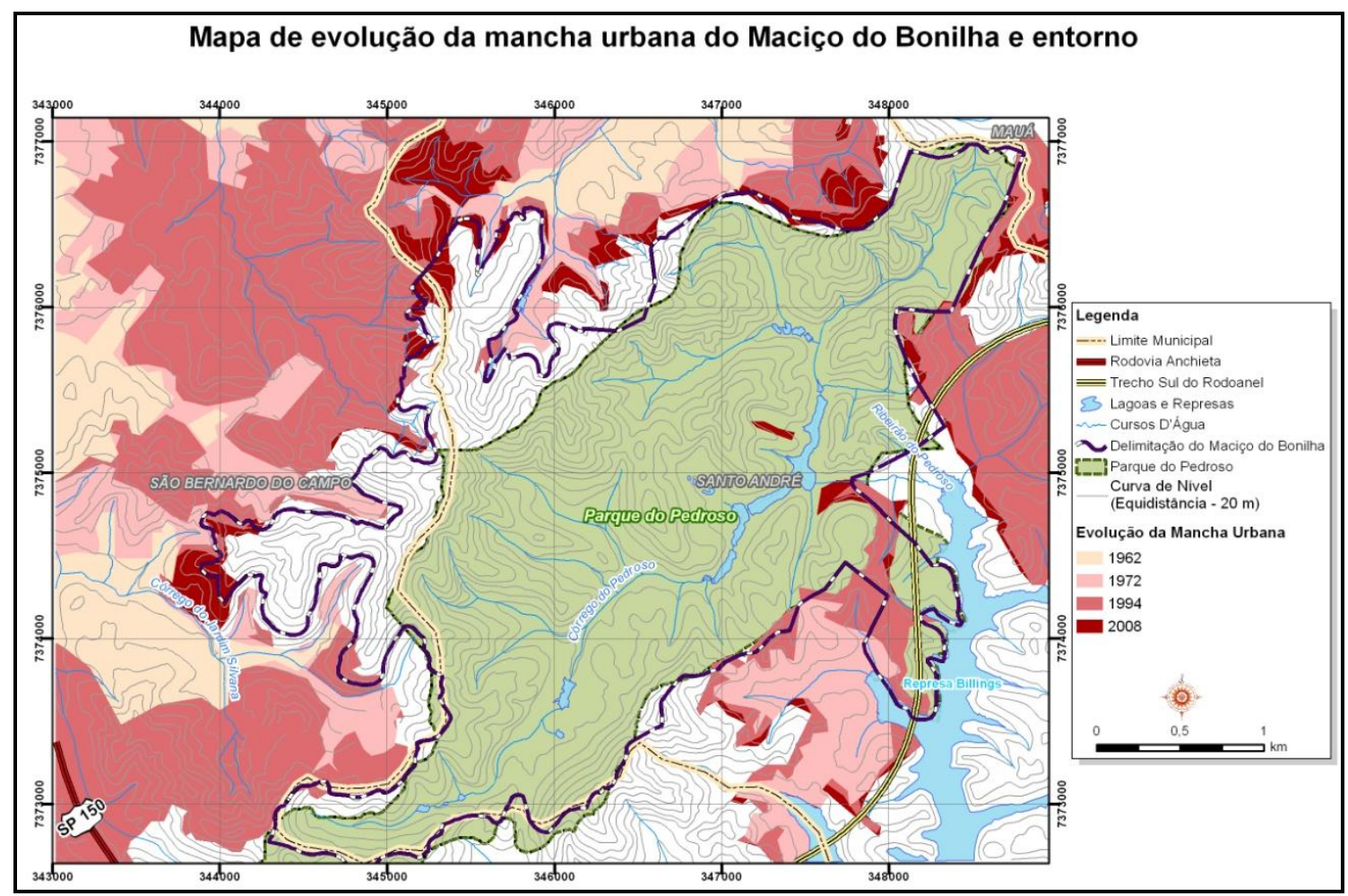

Figura 4 - Fases de evolução da mancha urbana na área de estudo.

Tabela 2 - Valores percentuais relativos à evolução da mancha urbana e a área total

\begin{tabular}{cc}
\hline Ano & Porcentagem (\%) \\
\hline 1962 & 8 \\
1972 & 18 \\
1994 & 44 \\
2008 & 48 \\
\hline
\end{tabular}




\section{Intervenções da Urbanização nos Processos Geomorfológicos}

$\mathrm{Na}$ área de estudo existe uma modificação da paisagem por meio da crescente urbanização. A ocupação das encostas que apresentam riscos fica comprometida pela precariedade das construções, pelo despejo de lixo nas encostas, pela ausência de obras de drenagem e pelo encharcamento do terreno promovido pela infiltração de esgotos provenientes de fossas individuais, sendo que em períodos chuvosos há o agravamento dos riscos, em especial os deslizamentos.

Segundo o Plano Municipal de Redução de Riscos (PMRR), em que foram mapeadas todas as áreas de risco do município, parte da região estudada é apontada como o local com maior perigo de desmoronamento (SÃO BERNARDO DO CAMPO, s.d.). No município de Santo André a situação é semelhante, com existência de áreas de risco e deslizamentos em períodos de fortes chuvas, culminando com perdas de vidas humanas em algumas ocasiões. Atentando-se a esses fatos, foi elaborado um mapa de susceptibilidade a deslizamentos para a área do Maciço e de seu entorno (Figura 5), baseado em variáveis sociais (processo de industrialização, evolução da mancha urbana e uso do solo) e variáveis físicas (declividade, formas de encosta, litologia, processos) diagnosticadas na região. Foi dada maior atenção a esta última variável por ela apresentar-se relevante no desencadeamento de deslizamentos e por apresentar altos índices de declividade na referida área.

Áreas acima de 850 metros de altitude, com declividade superior a 30\%, faces preferencialmente voltadas para sul e sudeste com ocupação antrópica representam a classe instalada de susceptibilidade. A classe potencial de susceptibilidade se caracteriza por áreas entre 850 e 760 metros de altitude, declividade superior a 30\% e não ocupada. Por fim, a classe baixa apresenta declividade inferior a $30 \%$ e 760 metros de altitude, com ou sem ocupação.

Desta forma pode-se observar como a urbanização interfere/acelera os processos de deslizamentos e ao mesmo tempo sofre os danos ambientais, sociais e econômicos do desdobramento desse processo.

De modo a conferir e validar os produtos cartográficos confeccionados realizou-se trabalhos de campo, em que foram verificadas diversas áreas susceptíveis a deslizamentos, sendo representativas do propósito do estudo. São áreas que apresentam pontos de 
deslizamentos, estão assentadas num sítio físico declivoso, com presença maciça de autoconstruções e moradias precárias (Figura 6).

Analisando sob o viés da Geomorfologia Antrópica é possível perceber que a urbanização age como aceleradora dos processos geomorfológicos, apresentando setores que apresentam riscos aos moradores em que muitos deles encontram-se interditados pela Defesa Civil, conforme pode ser verificado em campo.

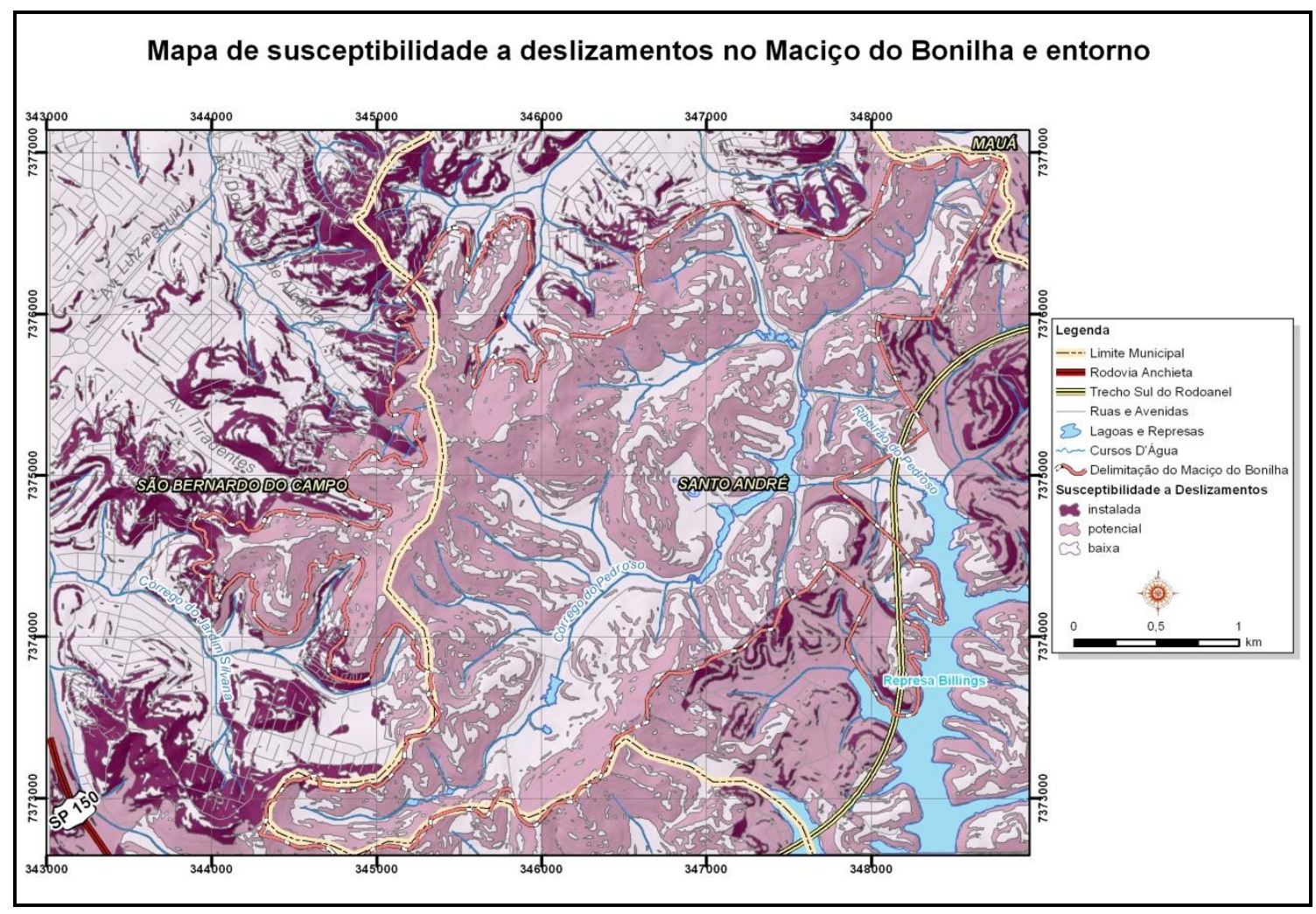

Figura 5 - Mapa de Susceptibilidade a deslizamentos no Maciço do Bonilha e entorno

De modo a analisar dois setores com susceptibilidades diferentes, comparamos a favela do Montanhão e o Parque Regional do Pedroso, mostrando como a sociedade com uma urbanização desenfreada pode acelerar os processos naturais da região e, de outro lado, como a conservação de áreas naturais pode ajudar a "frear" tais processos, causando assim menos danos a própria natureza e a sociedade.

A favela do Montanhão (Figura 3), em São Bernardo, é densamente ocupada por autoconstruções, e se configura numa área susceptível. Possui variação altimétrica entre 823 e 889 metros, com vertentes voltadas para S e SE, sofrendo pouca insolação e assim sendo mais úmidas e declividade maiores que $30 \%$. Apresenta a configuração de um quadro de risco à ocupação, em que a urbanização desenfreada, por meio da favelização de uma 
parcela da população se vê obrigada a morar em um setor da cidade com risco inerente pela sua configuração geomorfológica.

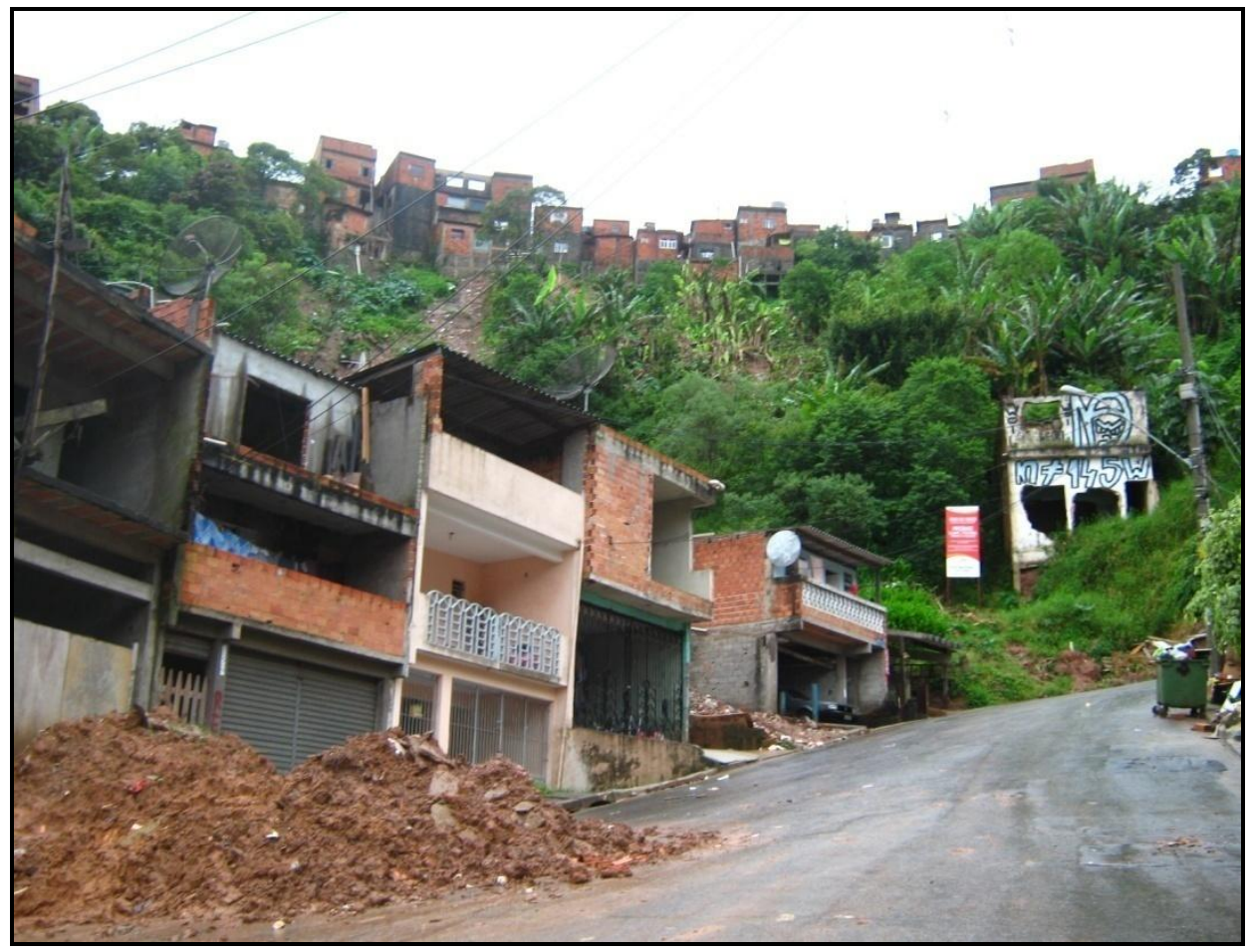

Figura 6 - Casas no alto do morro e vista de parte da rua da Bica, configurando-se em uma setor fortemente atingido com os deslizamentos ocorridos nos primeiros meses de 2010, estando localizadas na área de susceptibilidade instalada (06/03/2010)

Já a área referente à Unidade de Conservação do Parque do Pedroso (Figura 7) apresenta classe potencial (setores mais altos) e baixa (setores de planícies). É uma área não ocupada, estando dentro da UC do Parque do Pedroso, com vegetação nativa em abundância. Possui variação altimétrica entre 690 e 770 metros, vertentes voltadas para S e SW, preferencialmente, e declividades inferiores a 30\%. Neste trecho analisado, os riscos são menores, pois não há ocupação e o risco potencial se restringe aos pequenos morros da área, porém com estabilidade maior que as demais áreas analisadas, por estarem recobertos com vegetação nativa.

Os resultados apresentados possibilitam pensar a área de estudo como um espaço construído com muitos elementos perturbadores de sua topografia (superfícies pavimentadas, materiais de construção, canalização, etc.), tendo modelados decorrentes da forma de ocupação urbana (NIR, 1983) e assim modificando os processos geomorfológicos existentes (GOUDIE, 1986). 


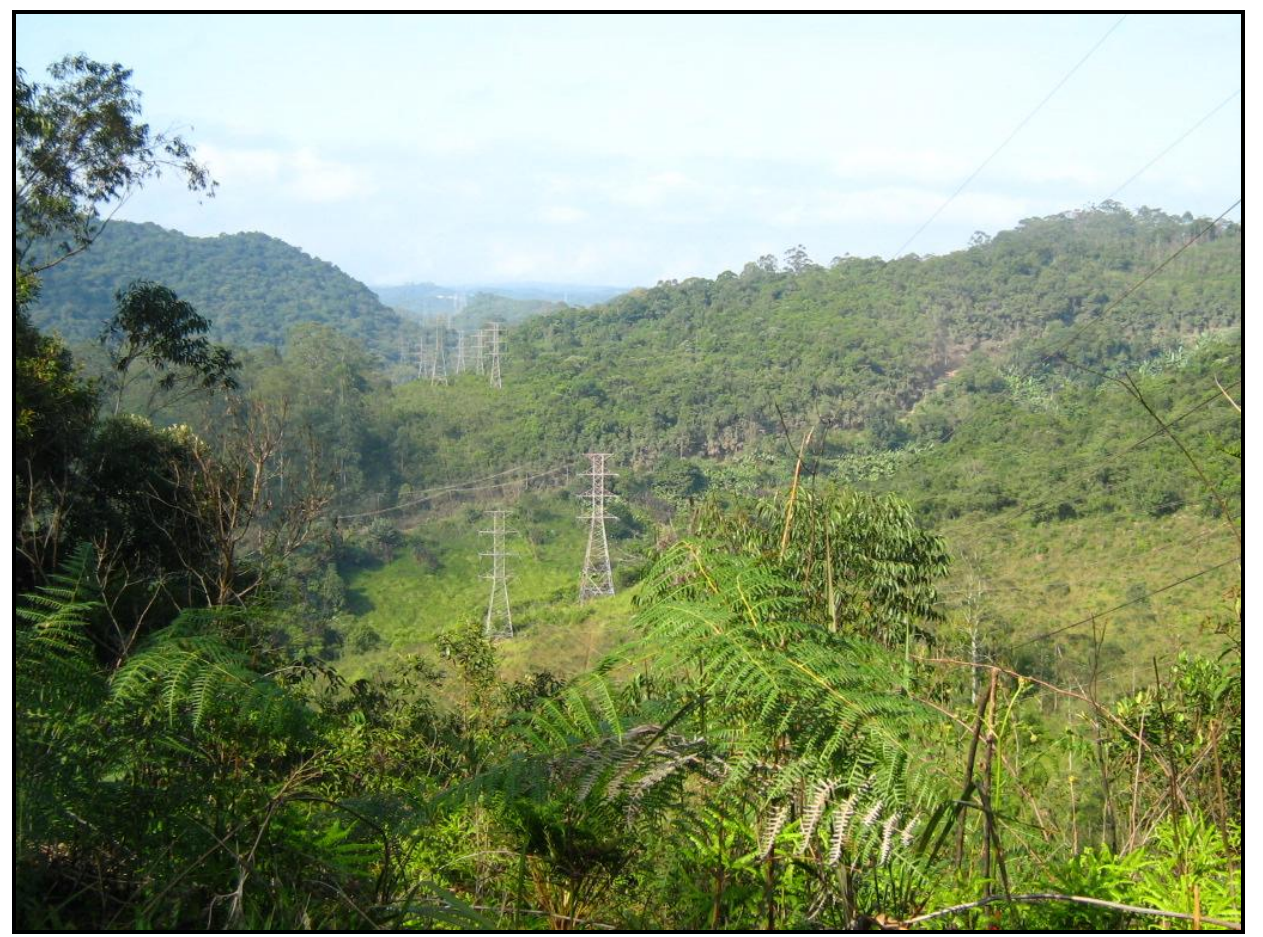

Figura 7 - Vista do UC Parque do Pedroso, localizado, preferencialmente, na classe de susceptibilidade baixa $(14 / 05 / 2008)$

Outros trabalhos que apresentam a mesma proposta, analisando os aspectos da ocupação antrópica no modelado do relevo vem sendo desenvolvidos nas últimas décadas, em grande parte graças ao avanço e melhoria dos recursos informacionais científicos e metodológicos, por exemplo, Busoni et al. (1995), Caldara e Simone (2004), Jesus (2004), Albarnoz et al. (2007) e Lazzari et al. (2009) para citar alguns.

O processo de desenvolvimento apresentado para o mapeamento de áreas susceptíveis a deslizamentos é uma ferramenta simples e eficaz no gerenciamento e monitoramento de áreas que apresentam riscos naturais, podendo ser utilizada por pesquisadores, gestores públicos, entre outros. No que tange à aquisição de dados para efetuar tais mapeamentos, existem certas limitações, haja vista que certas bases de dados não são facilmente disponibilizadas pelos agentes que as armazenam, como é o caso do mapeamento das áreas de risco municipal, elaborado pela Defesa Civil, que podem limitar parte do trabalho. Neste caso, é imprescindível um trabalho de campo detalhado a fim de minimizar essa lacuna. 


\section{CONCLUSÕES}

A partir do mapa de susceptibilidade a deslizamentos, áreas acima de 850 metros de altitude, com declividade superior a $30 \%$, faces preferencialmente voltadas para sul e sudeste com ocupação antrópica, representam a classe instalada de susceptibilidade, agravando-se com os eventos pluviométricos intensos na época do verão associados a ocupação antrópica desenfreada. São áreas em que o poder público deve tomar medidas emergenciais por meio da manutenção e monitoramento das mesmas, pois além de causar instabilidade para a própria área, atinge as áreas adjacentes, no caso áreas de classes potencial e baixa susceptibilidade.

Reitera-se mais uma vez a importância da caracterização e mapeamento de áreas sujeitas a risco, elaboração do histórico de ocorrência dos últimos eventos, estabelecimento de sua freqüência e magnitude, prevendo a ocorrência e localização de eventos futuros, o monitoramento das alterações geomorfológicas e usar o conhecimento da dinâmica geomorfológica para produzir e gerir estratégias de mitigação apropriadas para cada local atingido por eventos de desastre natural.

Levando tudo isto em consideração, a área de estudo insere-se em uma região de características físicas desfavoráveis e com expressiva ocupação urbana, ocasionando uma forte pressão antropogênica sobre o relevo, que consequentemente é ocasiona por problemas referentes à moradia, ocupação sem prévia instalação de infraestrutura básica, entre outros e fazendo parte de um processo de ocupação caótica fruto de uma "falta de planejamento" em que certos interesses são direcionados a favor de alguns em detrimento de outros.

Por fim, buscou-se discutir ao longo do trabalho que devido às características naturais, a área de estudo se encontra numa situação de vulnerabilidade ambiental, aumentado com a interferência da sociedade, no caso principalmente pela urbanização por meio de autoconstruções e moradias precárias, e assim acelerando os processos geomorfológicos e trazendo consequências catastróficas.

\section{REFERÊNCIAS BIBLIOGRÁFICAS}

ABREU, A. A. Significado e propriedades do relevo na organização do espaço. Boletim de Geografia Teorética. Rio Claro, n. 15, 1985, p. 154-162. 
AB'SABER, A. N. Geomorfologia do Sítio Urbano de São Paulo. São Paulo: Ateliê Editorial, 1957. 360p.

ALBARNOZ, K. M.; MUÑETÓN, E. G.; GALBÁN, E. M. Influencia de la intervención antrópica em la ocurrencia de processos de ladera. Microcuenca de La Quebrada Ramos, flanco norandino venezolano. Terra Nueva Etapa. v. XXIII, n. 34, 2007, p. 35-68

ALCÁNTARA-AYALA, I. Geomorphology, natural hazards, vulnerability and prevention of natural disasters in developing countries. Geomorphology. v. 47, n. 2-4, 2002, p. 107-124.

ALMEIDA, F. F. M. O Planalto Paulistano. A Cidade de São Paulo. 1 v.: Cia. Ed. Nacional AGB/SP, 1958. Capítulo 4, p. 113-167.

Fundamentos Geológicos do Relevo Paulista. São Paulo: IGEOG (Série Teses e Monografias) 14, 1974, 111p.

AZEVEDO, A. (Org.) A Cidade de São Paulo. 1 v.: Cia. Ed. Nacional - AGB/SP, 1958.

BUSONI, E., SANCHIS, P. S., CALZOLARI, C., ROMOGNOLI, A. Mass movement and erosion hazard patterns by multivariate analysis of landscape integrated data: the Upper Orcia River Valley (Siena, Italy) case. Catena, v. 25, 1995, p.169-185.

CALDARA, M.; SIMONE, O. Coastal changes in the Eastern Tavoliere Plain (Apulia, Italy) during the Late Holocene: Natural or Anthropic? Quaternary Science Reviews, v. 24, 2005, p. 2137-2145.

CARLOS, A. F. A. A metrópole de São Paulo no contexto da urbanização contemporânea. Revista de Estudos Avançados. São Paulo: IEA/USP, n. 66, 2009, p. 303-316.

DENALDI, R. Santo André. Urbanização de favelas e inclusão social. Ambiente Construído, Porto Alegre, v.4, 2004, p.7 - 20.

EMPRESA METROPOLITANA DE PLANEJAMENTO DA GRANDE SÃO PAULO S. A. (EMPLASA). Carta Topográfica: 1:10 000, Folha De Marchi. SF - 23-Y - C - VI-2 - SE - F, 1980. . Carta Topográfica: 1:10 000, Folha Pedroso. SF - 23-Y - D - IV - 1-SO - E, 1980. 
FUJIMOTO, N. S. V. M. Implicações ambientais na área metropolitana de Porto Alegre - RS: um estudo geográfico com ênfase na Geomorfologia Urbana. São Paulo: GEOUSP - Espaço e Tempo, n. 12, 2002. 35 p.

GOMES, R. C. C.; SILVA, A. B.; SILVA, V. P. Política habitacional e urbanização do Brasil. Scripta Nova. Revista electrónica de Geografía y Ciencias Sociales. Barcelona: Universidad de Barcelona, v. VII, n. 146 (083), 2003. Disponível em <http://www.ub.es/geocrit/sn/sn146(083).htm> Acesso em: 18 ago. 2010.

GOUDIE, A. S. The human impact on the natural environment. Oxford: Blackwell, 2 ed., 1986. 511p.

HUECK, K. Mapa fitogeográfico do Estado de São Paulo. Boletim Paulista de Geografia, São Paulo, n. 22, 1956, p. 19-25.

JESUS, A. S. Geomorfologia antrópica, riscos geomorfológicos e hidrológicos na porção centro-leste de Anápolis (GO). Boletim Goiano de Geografia. V. 24, n. 1-2, 2004, p. 70-79.

KOWARICK, L. A Espoliação Urbana. Rio de Janeiro: Paz e Terra, 1979. 204p.

LAZZARI M., DANESE M. AND MASINI N. A new GIS based integrated approach to analyze the anthropic-geomorphological risk and recovery the vernacular architecture. Journal of Cultural Heritage, v. 10, 2009, p.104-111.

MARICATO, E. Brasil, cidades, alternativas para a crise urbana. Petrópolis: Vozes, 2001.

MATARAZZO-NEUBERGER, W. M. Avifauna urbana de dois municípios da Grande São Paulo, São Paulo. São Paulo, 1986. Dissertação (Mestrado em Zoologia) - Instituto de Biologia da Universidade de São Paulo.

MEYER, R. M. P.; GROSTEIN, M. D.; BIDERMAN, C. São Paulo Metrópole. São Paulo: Imprensa Oficial, 2004. 296p.

NIR, D. Man, a geomorphological agent. Jerusalem, Israel: Keter Publishing House, 1983. $165 \mathrm{p}$ 
OKUDA, S. On the relation between physical geomorphology and the science of natural disasters. Bull. Disaster Prev. Res. Inst. v. 19, n. 25, 1970.

PELOGgIA, A. U. G. O Homem e o Ambiente Geológico: geologia, sociedade e ocupação urbana no Município de São Paulo. São Paulo: Xamã, 1998. 270p.

ROSENFELD, C. L. The geomorphological dimensions of natural disasters. Geomorphology. v. 10,1994 , p. $27-36$.

SÃO PAULO. Governo do Estado. Secretaria do Meio Ambiente. Estudo de Impacto Ambiental (EIA) - Programa Rodoanel Mario Covas Trecho Sul Modificado. v.III, 2004.

SANTOS FILHO, R. D. Antropogeomorfologia da ocupação de áreas de risco em Petrópolis (RJ): análise ambiental urbana. 2007. 271p. Tese (Doutorado em Geografia) - Instituto de Geografia da Universidade Federal do Rio de Janeiro.

SCIFONI, S. \& MARTINS, S. M. P. Caracterização e diagnóstico ambiental do Maciço do Bonilha, 1997. Estudo elaborado para subsidiar o tombamento do Maciço do Bonilha. 1997, $15 p$.

VERSTAPPEN, H. T. Geomorphology, natural disasters and global change. Symposium on Aerospace Survey and Natural Disasters. ITC Journal. v. 3-4, 1989, p.159- 164.

VIEIRA, C. V.; FURTADO, S. M. A. Caracterização dos aspectos físico-naturais intrínsecos da encosta e identificação das áreas susceptíveis a deslizamentos na sub-bacia do Ribeirão Araranguá - Blumenau/SC. In: Simpósio Brasileiros de Desastres Naturais, 1., 2004, Florianópolis. Anais... Florianópolis: GEDN/UFSC, 2004. p. 337-351. (CD-ROM)

\section{Artigo recebido em 15/03/2012.}

Artigo aceito em 05/12/2012. 